\title{
Effectiveness of dexamethasone injection in the pterygomandibular space before and after lower third molar surgery
}

\author{
Kalaya Sitthisongkhram¹, Nattisa Niyomtham², Teeranut Chaiyasamut', Verasak Pairuchvej", Kumar KC', \\ Natthamet Wongsirichat ${ }^{2}$ \\ 'Department of Oral Maxillofacial Surgery, Faculty of Dentistry, Mahidol University, Bangkok, Thailand \\ ${ }^{2}$ International College of Dentistry, Walailak University, Bangkok, Thailand
}

\begin{abstract}
Background: Previous studies have investigated the effects of dexamethasone injections into the pterygomandibular space and compared them to those of controls; however, the effects of dexamethasone injections before and after lower third molar surgery on postoperative complications have not been studied. This research investigated the postoperative sequelae of dexamethasone injections before and after surgery into the pterygomandibular space. The aim of this study was to evaluate the effects of preoperative and postoperative injections of $4 \mathrm{mg}$ of dexamethasone into the pterygomandibular space on postoperative pain, facial swelling, and the restriction of mouth opening following lower third molar surgical removal.

Methods: Twenty-seven participants with bilateral symmetrical lower impacted third molars were included in this study. Each participant was randomly allocated to one of two groups. Group A received injections of $1 \mathrm{ml}$ dexamethasone $(4 \mathrm{mg} / \mathrm{mL}$ ) and $1 \mathrm{~mL}$ placebo into the pterygomandibular space before and after surgery, respectively. Group B received the same doses of placebo before surgery and dexamethasone after surgery. Results: A significant restriction of mouth opening on the second postoperative day was observed in both groups. Nonetheless, the postoperative restriction of mouth opening, facial swelling, postoperative pain, and analgesic consumption after lower third molar surgical removal were not significantly different in the two groups. Conclusions: Regardless of the time of administration, dexamethasone injections into the pterygomandibular space resulted in satisfactory control of the postoperative sequelae of the mandibular third molar surgical removal.
\end{abstract}

Keywords: Dexamethasone; Postoperative Complications; Pterygomandibular space; Surgical Removal; Third Molar.

This is an Open Access article distributed under the terms of the Creative Commons Attribution Non-Commercial License (http://creativecommons.org/licenses/by-nc/4.0/) which permits unrestricted non-commercial use, distribution, and reproduction in any medium, provided the original work is properly cited.

\section{INTRODUCTION}

The surgical extraction of lower impacted third molars (LITMs) is a routine procedure within oral and maxillofacial surgery. Although it is a routine and minor procedure, most patients suffer from several postoperative sequelae such as restricted mouth opening, pain, and facial swelling.
The administration of corticosteroids after the surgical extraction of lower third molars has been widely used to control postoperative sequelae [1,2]. Dexamethasone is a frequently studied and used drug because of its longer duration of action and greater anti-inflammatory potency. When compared with other corticosteroids, it has little to no side effects $[3,4]$.

Several studies have compared the effects of dexamethasone after LITM extraction, as shown in the

Received: August 4, 2020 - Revised: September 21, 2020 - Accepted: October 4, 2020

Corresponding Author: Teeranut Chaiyasamut, Department of Oral \& Maxillofacial Surgery, Faculty of Dentistry, Mahidol University, 6 Yothi Street Rachathewee

District Bangkok 10400 Thailand

E-mail: teeranut.cha@gmail.com

Copyright(c) 2020 Journal of Dental Anesthesia and Pain Medicine 
Table 1. The inclusion criteria, exclusion criteria and withdrawal criteria for this study

\begin{tabular}{|c|c|}
\hline Inclusion criteria & Exclusion criteria \\
\hline $\begin{array}{l}\text { 1. Age of participants between } 18 \text { and } 30 \text { years } \\
\text { 2. Participants with asymptomatic bilateral symmetrical partially or } \\
\text { totally impacted lower third molars classified as the inclination } \\
\text { according to the Winter classification [20] and position according } \\
\text { to the Pell and Gregory classification [21]. } \\
\text { 3. This study required flap opening, bone removal, and tooth } \\
\text { separation during the operation. } \\
\text { 4. The operation site was free from infection and inflammation at } \\
\text { the time of operation. }\end{array}$ & $\begin{array}{l}\text { 1. Participants with systemic disorders contraindicated the surgical procedure. } \\
\text { 2. Facial deformities of the participants that may interfere with the injections } \\
\text { during the operation or the evaluation. } \\
\text { 3. Smoking, alcoholism, pregnancy or lactation. } \\
\text { 4. Allergy to drugs or other substances used in this study. } \\
\text { 5. Analgesic intake within the } 2 \text { weeks before surgery. } \\
\text { 6. Usage of other drugs besides the drugs in this study. } \\
\text { 7. Inability to honor the follow-up appointments and refusal to participate in } \\
\text { the study. } \\
\text { 8. Surgical duration exceeding } 60 \text { minutes. } \\
\text { 9. Any surgical complications occurred that would render the non-comparable } \\
\text { procedures. }\end{array}$ \\
\hline
\end{tabular}

previous articles [2-19].

However, studies on dexamethasone injections through the pterygomandibular space $[10-13,16,17]$ in LITM surgery are limited.

Therefore, this study was conducted to evaluate the effects of preoperative and postoperative $4 \mathrm{mg}$ dexamethasone injection through the pterygomandibular space on postoperative pain, facial swelling, and restricted mouth opening to determine the best period of administration for LITM extraction.

\section{METHODS}

\section{The study with ethic approval}

This prospective, randomized, split-mouth, crossover clinical study was conducted at the Oral and Maxillofacial Surgery clinic of the Faculty of Dentistry, Mahidol University. It was approved by the Mahidol University Institutional Review Board (MU-IRB) with COA. No. MU-DT/PY-IRB 2018/029.1505.

\section{The sample size calculation}

The sample size calculation was based on parameters obtained from a previous study using the formula with $\alpha=0.05, \beta=0.2$. Therefore, this study required a minimum of 26 participants. Considering a 20\% compensation for possible loss and withdrawal of cases, the sample size was increased to 31 participants.

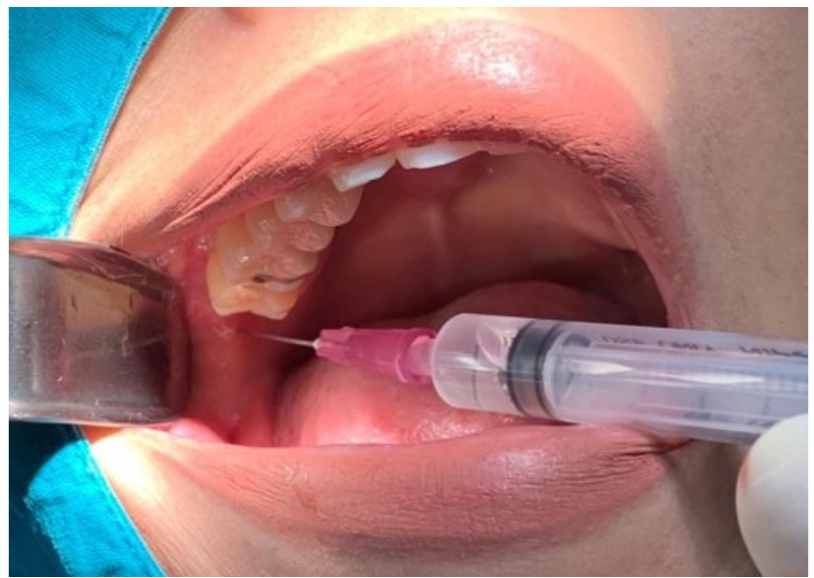

Fig. 1. One milliliter of dexamethasone (4 milligrams) or one milliliter of normal saline injected through the pterygomandibular space immediately before and after surgery.

$$
n=\frac{\left(z_{\alpha / 2}+z_{\beta}\right)^{2} \sigma^{2}}{d^{2}}
$$

\section{The criteria for patient selection}

The inclusion, exclusion, and withdrawal criteria used in this study is illustrated in Table 1.

The participants who met the criteria of this study were informed about the objectives and details. All participants who agreed to participate signed the informed consent document. For each participant, personal data, including name, gender, age, demographic profile, current and previous medical and dental history, were obtained.

The participants had similar bilateral LITMs; therefore, the researcher randomly divided the sides of impaction into two equal groups using a sealed letter containing the 
Table 2. The assessment methods for facial swelling, restriction of mouth opening, and pain

\begin{tabular}{|c|c|c|c|}
\hline Variability & Methods & Unit & Article following \\
\hline Facial swelling (Fig. 2) & $\begin{array}{l}\text { (A): Lateral canthus of the eye to the gonion angle. } \\
\text { (B): Tragus to the commissure of the mouth. } \\
\text { (C): Tragus to the soft tissue pogonion. }\end{array}$ & millimeters & $\begin{array}{l}\text { Schultze-Mosgau et al. [22] } \\
\text { and Antunes et al. [9] }\end{array}$ \\
\hline Limitation of mouth opening & $\begin{array}{l}\text { The maximum mouth opening taken from the distance } \\
\text { between the upper and lower incisal edges of central } \\
\text { incisors. }\end{array}$ & millimeters & $\begin{array}{l}\text { Schultze-Mosgau et al. } \\
\text { [22] and Antunes et al. } \\
\text { [9] and Boonsiriseth [4] }\end{array}$ \\
\hline \multicolumn{4}{|c|}{ Pain evaluation } \\
\hline Visual analog scale (VAS) & $\begin{array}{l}\text { The horizontal } 100-\mathrm{mm} \text { long line starting from } \\
0 \text { on the left-end as "no pain" and } \\
100 \text { on the other right-end as the "worst pain" measured } \\
\text { on the day of operation, } 2^{\text {nd }} \text { and } 7^{\text {th }} \text { postoperativedays. }\end{array}$ & millimeters & $\begin{array}{l}\text { Katz \& Melzack [23] and } \\
\text { Sirintawat [24] }\end{array}$ \\
\hline $\begin{array}{l}\text { Interpretation from VAS to the } \\
\text { numeric rating scale (NRS) }\end{array}$ & $\begin{array}{l}\text { no pain }(0-4 \mathrm{~mm}) \text {, } \\
\text { mild pain }(5-44 \mathrm{~mm}) \text {, } \\
\text { moderate pain }(45-74 \mathrm{~mm}) \\
\text { severe pain }(75-100 \mathrm{~mm})\end{array}$ & number & $\begin{array}{l}\text { Jensen et al. [25] and } \\
\text { Boonsiriseth [4] } \\
\text { and Sirintawat [24] }\end{array}$ \\
\hline The number of analgesic tablets & \multicolumn{3}{|c|}{$\begin{array}{l}\text { The analgesic tablets taken was recorded each day for } 7 \text { Number of tablets Boonsiriseth [4] } \\
\text { days postoperatively. }\end{array}$} \\
\hline
\end{tabular}

code for the timing of the injection of $4 \mathrm{mg}$ dexamethasone.

Group A received injections of $1 \mathrm{~mL}$ dexamethasone (4 $\mathrm{mg} / \mathrm{ml}$ ) and $1 \mathrm{~mL}$ normal saline as placebo in the pterygomandibular space before and after the surgical removal of the LITM, respectively (Fig. 1).

Group B received injections of the same dose of normal saline as placebo before surgery and dexamethasone after surgery into the pterygomandibular space.

Each participant underwent two surgical procedures performed by the same surgeon, with a washout period of four weeks between them.

\section{Method of operation}

Before the surgical procedure, a single non-operating assistant prepared two identical syringes that contained $1 \mathrm{~mL}$ of dexamethasone and normal saline, respectively. Both the surgeon and the participant were blinded to the dexamethasone usage. Local anesthesia was performed by the administration of $4 \%$ articaine 1 : 100,000 epinephrine to the inferior alveolar nerve, lingual nerve, and buccal nerve block, and objective signs of anesthesia were apparent. All participants received $1 \mathrm{ml}$ of $4 \mathrm{mg}$ dexamethasone or $1 \mathrm{ml}$ normal saline injection depending on their randomly allocated group through the pterygomandibular space at the same site where the inferior alveolar nerve block was performed.

The standard technique of LITM surgical removal was performed subsequently, which involved incision and the reflection of the mucoperiosteal flap followed by bone removal, tooth section, and tooth removal. The remaining soft tissue or dental follicles in the socket were curetted followed by irrigation. The surgical wound was sutured with black silk sutures after adequate hemostasis was secured.

The duration of surgery, in minutes, began from the initial incision and ended at the closing suture. Immediately after the LITM surgical removal, the participant received another $1 \mathrm{~mL}$ dexamethasone or normal saline injection through the soft tissue at the same site of the preoperative process.

After the surgical procedure, all participants received routine postoperative instructions. Amoxicillin $500 \mathrm{mg}$ four times daily for 5 days and acetaminophen $500 \mathrm{mg}$ for every 6 hours for pain were prescribed.

\section{The evaluation of each measurement methods}

All assessments, including evaluations of facial swelling, restriction of mouth opening, and pain, were performed by a single surgeon, as shown in Table 2 . 


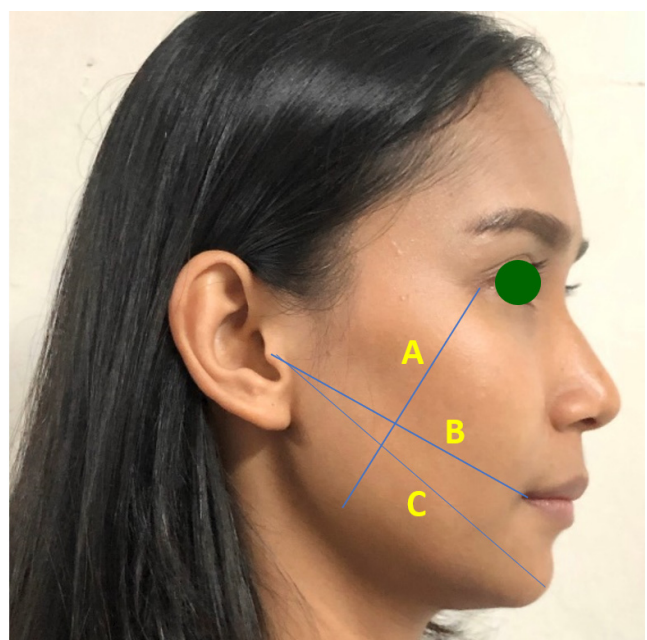

Fig. 2. Three linear facial swelling measurements. Remarks A: Ex-Go, lateral canthus of the eye to the gonion angle; $\mathrm{B}$ : Tr-Ch, tragus to the commissure of the mouth; $\mathrm{C}$ : Tr-Pg, tragus to the soft tissue pogonion

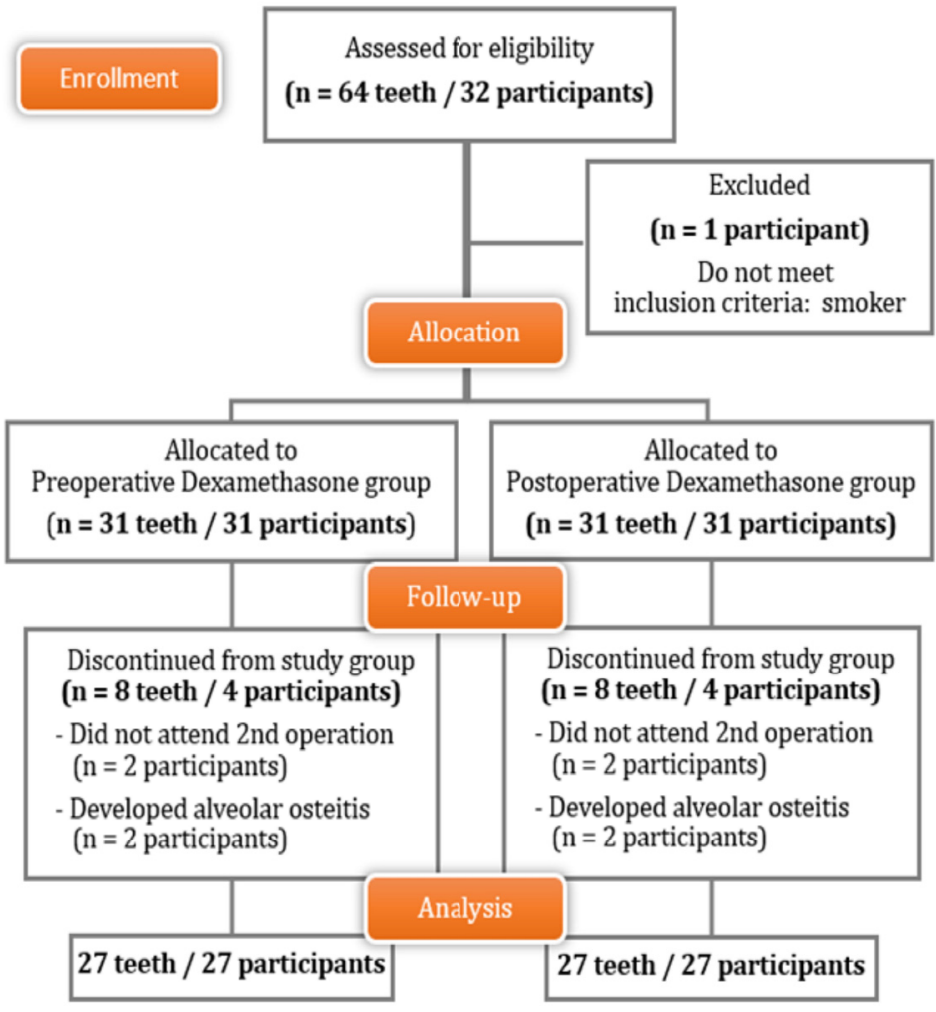

Fig. 3. CONSORT diagram detailing participant recruitment and follow-up in the study

\section{Data analysis}

All the coded data were inputted into the Microsoft Excel spreadsheet and analyzed using the SPSS Statistical Package for the Social Sciences (SPSS Version 18.0 for Windows, Chicago, IL, USA). The level of significance was set at $\mathrm{P}<0.05$. The significance of the differences between the preoperative and postoperative dexamethasone groups was assessed using paired t-test and Wilcoxon signed rank test. The Friedman two-way analysis of variance was used to analyze the significance of the differences between the dependent variables. 
Table 3. Measurements of facial swelling (in millimeters): mean values and differences from preoperative baseline values in the study groups

\begin{tabular}{|c|c|c|c|c|}
\hline Distance measurement & Evaluation day & $\begin{array}{l}\text { Group A } \\
\text { Mean (SD) }\end{array}$ & $\begin{array}{l}\text { Group B } \\
\text { Mean (SD) }\end{array}$ & P-value \\
\hline \multirow[t]{6}{*}{ Ex-Go } & Operation day (preop baseline) & $106.61(5.66)$ & $104.58(6.01)$ & 0.066 \\
\hline & Second postop day & $107.50(6.76)$ & $106.16(5.70)$ & 0.371 \\
\hline & Seventh postop day & $108.27(6.09)$ & $105.62(5.58)$ & 0.106 \\
\hline & \multicolumn{4}{|c|}{ Differences } \\
\hline & Second postop day to baseline & $0.89(4.10)$ & $1.58(3.74)$ & 0.545 \\
\hline & Seventh postop day to baseline & $1.66(4.67)$ & $1.03(4.32)$ & 0.654 \\
\hline \multirow[t]{6}{*}{ Tr-Ch } & Operation day (preop baseline) & $113.18(8.18)$ & $112.59(9.03)$ & 0.492 \\
\hline & Second postop day & $113.89(7.79)$ & $114.23(8.67)$ & 0.730 \\
\hline & Seventh postop day & $113.33(8.07)$ & $112.87(8.40)$ & 0.569 \\
\hline & \multicolumn{4}{|c|}{ Differences } \\
\hline & Second postop day to baseline & $0.71(2.49)$ & $1.64(2.31)$ & 0.189 \\
\hline & Seventh postop day to baseline & $0.15(2.39)$ & $0.28(2.44)$ & 0.846 \\
\hline \multirow[t]{6}{*}{$\mathrm{Tr}-\mathrm{Pg}$} & Operation day (preop baseline) & $140.11(10.76)$ & $140.60(10.34)$ & 0.400 \\
\hline & Second postop day & $142.28(9.38)$ & $142.29(10.09)$ & 0.943 \\
\hline & Seventh postop day & $141.08(10.03)$ & $140.39(10.61)$ & 0.429 \\
\hline & \multicolumn{4}{|c|}{ Differences } \\
\hline & Second postop day to baseline & $2.17(3.30)$ & $1.69(2.36)$ & 0.493 \\
\hline & Seventh postop day to baseline & $0.97(3.42)$ & $-0.21(2.24)$ & 0.193 \\
\hline
\end{tabular}

Remark: Ex-Go, lateral canthus of the eye to the gonion angle; Tr-Ch, tragus to the commissure of the mouth; Tr-Pg, tragus to the soft tissue pogonion; Group A, preoperative dexamethasone administration; Group B, postoperative dexamethasone administration.

\section{RESULTS}

A total of 31 healthy participants were initially enrolled in this study. Two of them did not report for follow up for the second surgery, and two other participants developed alveolar osteitis. Therefore, 4 participants were excluded, and the remaining 27 were included in the study without any withdrawal for data analysis.

The flow chart in Fig. 3 shows the enrolment process for the final participants.

Of the 27 participants, 10 were male (37\%) and 17 were female (63\%). The age range was 18-29 years with a mean of 22 years.

\section{Type of LITM in the study}

Fourteen participants had horizontal angulation (52\%), 10 had mesial angulation (37\%), and 3 had vertical angulation (11\%). According to the Pell and Gregory classification and the Winter classification, there were 17 participants with class IA (63\%), 2 with class IB (7\%), 6 with class IIB (22\%), 1 with class IIC (4\%), and 1 with class IIIB (4\%).

\section{Operation time in this study}

The mean durations of surgery were $20.24 \pm 8.09$ minutes for the preoperative dexamethasone group and $20.93 \pm 7.97$ minutes for the postoperative dexamethasone group, which were not significantly different $(\mathrm{P}>$ $0.5)$.

\section{The adverse effect from dexamethasone}

No adverse events were associated with any of the drugs used in this study. However, two participants experienced alveolar osteitis: one in the preoperative dexamethasone group and another in the postoperative dexamethasone group. However, both of them recovered within two weeks after the surgery; therefore, they were excluded from the data processing (Table 1). Postoperative infection, lower lip paresthesia, and other complications were not observed in either group during the course of the study.

\section{Facial swelling measurements}

Table 3 shows no significant difference between any of the two-point distances of the swelling measurements 
Table 4. Measurements of maximum inter-incisal distances (in millimeters): mean values and differences from preoperative baseline values in the study groups

\begin{tabular}{|c|c|c|c|}
\hline Evaluation day & $\begin{array}{c}\text { Group A } \\
\text { Mean (SD) }\end{array}$ & $\begin{array}{c}\text { Group B } \\
\text { Mean(SD) }\end{array}$ & P-value \\
\hline Operation day (preop baseline) & $51.00(6.60)$ & $51.97(7.35)$ & 0.173 \\
\hline Postop day 2 & $43.24(12.24)$ & $43.83(11.89)$ & 0.686 \\
\hline Postop day 7 & $50.50(7.59)$ & $50.64(8.59)$ & 0.822 \\
\hline P-value & $0.000^{*}$ & $0.000^{*}$ & \\
\hline \multicolumn{4}{|c|}{ Differences } \\
\hline Baseline to postop day 2 & $7.76(8.62)$ & $8.14(8.32)$ & 0.614 \\
\hline Baseline to postop day 7 & $0.50(3.65)$ & $1.33(3.68)$ & 0.212 \\
\hline
\end{tabular}

* Significant, $P<0.05$

Remark: Group A, preoperative dexamethasone administration; Group B, postoperative dexamethasone administration; Preop, preoperation; Postop, postoperation.

Table 5. Measurements of VAS pain scores (millimeters): mean values in the study groups

\begin{tabular}{lccc}
\hline Evaluation day & Group A & Group B & Pean (SD) \\
& Mean (SD) & $27.95(20.84)$ & 0.230 \\
\hline 12 hr. postop day & $35.75(25.24)$ & $18.25(19.08)$ & 1.000 \\
postop day 1 & $21.92(23.84)$ & $12.39(20.44)$ & 0.983 \\
postop day 3 & $11.48(17.93)$ & $6.08(10.47)$ & 0.586 \\
postop day 7 & $6.30(10.34)$ & $0.000^{*}$ & \\
P-value & $0.000^{*}$ & \\
\hline
\end{tabular}

${ }^{*}$ Significant, $P<0.05$

Remark: Group A, preoperative dexamethasone administration; Group B, postoperative dexamethasone administration; Postop, postoperation.

of the preoperative and postoperative dexamethasone groups. Postoperative swelling was not statistically different over time when linked with the preoperative measurements in both groups $(\mathrm{P}>0.05)$.

\section{Maximum inter-incisal distances measurements}

There was no significant difference between the maximum extents of mouth opening in the preoperative and postoperative dexamethasone groups at any time point $(\mathrm{P}>0.05)$ (Table 4). However, a significant decrease was observed in the maximum mouth opening on postoperative day 2 from the preoperative extent and that on postoperative day 7 in the preoperative dexamethasone group $(\mathrm{P}=0.001$ and $\mathrm{P}=0.000$, respectively) and the postoperative dexamethasone group $(\mathrm{P}=0.000$ and $\mathrm{P}=0.019$, respectively).

\section{VAS pain scores measurements}

Regarding pain, there was no significant difference between the VAS scores of the two groups $(\mathrm{P}>0.05)$.
Nevertheless, significant reductions in the VAS scores from the day of surgery to the 3rd and 7th postoperative days was observed in the preoperative dexamethasone group ( $\mathrm{P}=0.001$ and 0.000 , respectively) and the postoperative dexamethasone group (all $\mathrm{P}=0.000$ ). A significant decrease in the VAS scores from the 3rd to the 7th postoperative day $(\mathrm{P}=0.001)$ was also found in both groups, as shown in Table 5 .

\section{The analgesics taken}

The number of analgesics taken did not differ significantly across both groups $(\mathrm{P}>0.05)$. However, significant differences were found between the number of analgesics taken between the day of surgery and the 4th, 5th, and 6th postoperative days in the preoperative dexamethasone group, with P-values of $0.043,0.022$, and 0.004, respectively. Significant differences between the number of analgesics taken between the day of surgery and the 5th and 6th postoperative days were also observed in the postoperative dexamethasone group, with $\mathrm{P}$-values of 
Table 6. The number of analgesics taken (tablets): mean values in the study groups.

\begin{tabular}{lccc}
\hline Evaluation day & Group A & Group B & P-value \\
& Mean (SD) & Mean (SD) & 0.134 \\
\hline Operation day & $1.30(0.95)$ & $1.48(1.09)$ & 0.721 \\
Postop day 1 & $1(1.41)$ & $1.07(1.07)$ & 0.589 \\
Postop day 2 & $0.85(1.20)$ & $1.04(1.43)$ & $0.85(1.46)$ \\
Postop day 3 & $0.81(1.52)$ & $0.67(1.18)$ & 0.905 \\
Postop day 4 & $0.59(1.12)$ & $0.59(1.05)$ & 0.566 \\
Postop day 5 & $0.56(1.09)$ & $0.41(0.84)$ & 0.660 \\
Postop day 6 & $0.41(0.69)$ & $6.11(6.71)$ & 1.000 \\
Total & $5.52(7.12)$ & $0.000^{*}$ & 0.329 \\
P-value & $0.000^{*}$ & & \\
\hline
\end{tabular}

*Significant, $P<0.05$

Remark: Group A, preoperative dexamethasone administration; Group B, postoperative dexamethasone administration; Postop, postoperation.

0.047 and 0.003 , respectively, as shown in Table 6 .

\section{DISCUSSION}

Several previous studies have confirmed the antiinflammatory property of perioperative dexamethasone for controlling the sequelae of LITM extraction with its long-acting action and short-term safety [1-4,19]. In the current study, two participants developed alveolar osteitis and recovered within two weeks postoperatively. Two participants were lost to follow-up for the second surgery.

In previous review articles, the incidence of alveolar osteitis is reported between $1-5 \%$ of routine dental extractions, and it may increase to $38 \%$ of LITM extractions, which may depend on the severity of tissue injury [26,27]. Female gender and oral contraceptive usage are considered risk factors $[28,29]$. In the present study, alveolar osteitis $(3.33 \%)$ developed after two of 60 LITM surgical procedures. Both of the participants were female; one was on regular oral contraception.

Dexamethasone is not indicated for routine use LITM surgical removal; it is used in complicated operations. The difficulty of surgery and the prolonged duration resulted in extensive soft and hard tissue trauma, thus aggravating pain [30]. In this study, the LITM extraction involved bone removal and tooth sectioning, which is a difficult surgical consideration.

Additionally, this split-mouth crossover study on symmetrical bilateral LITM extractions by a single surgeon did not have significantly different durations of surgery in both dexamethasone groups $(\mathrm{P}>0.5)$.

Grossi et al. and Arora et al. compared the effects of perioperative submucosal injections of $4 \mathrm{mg}$ and $8 \mathrm{mg}$ dexamethasone and observed that a higher dose of dexamethasone was not superior to the lower dose regimen in reducing postoperative swelling after LITM surgical removal. Thus, the use of a minimal dose of dexamethasone was suggested [6,31]. A previous review by Ngeow and Lim suggested $4 \mathrm{mg}$ of dexamethasone as the lowest therapeutic dose for obtaining an anti-inflammatory effect [2].

To our knowledge, few studies have compared the effects of dexamethasone based on the timing of administration through the pterygomandibular space. The pterygomandibular space was selected as the site of delivery of dexamethasone in this study, given that it is a site for inferior alveolar nerve block injection that is highly enriched in vascular supply. This allows for better drug absorption and convenience for both patients and dental practitioners.

When a preoperative injection of $8 \mathrm{mg}$ dexamethasone into the pterygomandibular space after local anesthesia was administered, Latt et al. found that there was a significant reduction in postoperative pain compared with the control group [10].

Bhargava et al. stated that the co-administration of dexamethasone and a local anesthetic at the same 
injection site caused lesser injection pain, shorter anesthetic latency, and prolonged duration of soft tissue anesthesia [11]. Their latter study also reported similar plasma drug concentrations and clinical effects of $4 \mathrm{mg}$ dexamethasone injection through the pterygomandibular space and gluteus muscle [12]. In addition, a study by Bhargava et al. and Singh et al. found that dexamethasone injection through the pterygomandibular space caused similar postoperative clinical effects as administration by the consumption, intravenous, intramuscular, and submucosal routes [13,14].

Based on the findings of the present study, the effect of a preoperative injection of $4 \mathrm{mg}$ dexamethasone through the pterygomandibular space on postoperative pain, facial swelling, and the extent of mouth opening following LITM surgical removal was similar to that of a postoperative injection.

This finding is consistent with the reports in the review by Ngeow and Lim of the comparable effects of corticosteroids irrespective of their preoperative or postoperative administration [2]. However, other previous studies have had different results. Several previous reviews concluded that postoperative anti-inflammatory effects appeared to be greater when dexamethasone was administered before than immediately after LITM surgical removal [19,32,33].

To facilitate early suppression of the effects of inflammatory mediators, dexamethasone should be administered before the onset of the inflammatory process; postoperative administration only prevents further inflammatory progression.

From the results, no significant difference was found between any of the two-point facial swelling measurements of the preoperative and postoperative dexamethasone groups. Postoperative swelling was not significantly different over time compared with the preoperative values of both groups. Consistent with this result, Mojsa et al. found no statistically significant difference between the reductions in postoperative swelling in the preoperative and postoperative dexamethasone groups [17].
In contrast with this study, Al-Shamiri et al. found a greater reduction in postoperative swelling after preoperative than after postoperative administration of 8 mg dexamethasone [18].

Regarding the limitation of mouth opening after LITM surgical removal, this study revealed no significant difference between the maximum inter-incisal distances of the pre- and postoperative dexamethasone groups at any time point. This finding is comparable to that of the previous research by Mojsa et al. [17].

Nevertheless, on postoperative day 2, a significant restriction of mouth opening was observed in both groups. Hence, we assumed that the restriction of mouth opening occurred following LITM surgical removal, regardless of the time of dexamethasone administration. Al-Shamiri et al. found a similar significant reduction in the restriction of mouth opening from baseline to postoperative day 7 in both groups [18].

To assess postoperative pain, the VAS pain score and the number of analgesics taken were recorded by participants in a pain control form. Pain is a subjective perception that varies with individual background, life experience, and the degree of surgical difficulty $[23,30]$; therefore, the split-mouth crossover design was used in this study to reduce this bias. The maximum VAS scores of the preoperative and postoperative dexamethasone groups were evaluated on the day of surgery with a mean of $35.75 \pm 25.24 \mathrm{~mm}$ and $27.95 \pm 20.84 \mathrm{~mm}$, respectively. We converted the VAS pain score to the numeric rating scale, which was considered as mild pain $(5-44 \mathrm{~mm}$ ) based of the grading by Jensen et al. [25], Boonsiriseth et al. [4], and Sirintawat et al. [24] This study found that the numeric rating scale score decreased with time. Similar to the result of Al-Shamiri et al. [18], this study found no significant difference between the VAS scores of both dexamethasone groups. Our study finding contradicted the report by Mojsa et al. that better pain control was facilitated by postoperative than preoperative submucosal injection of dexamethasone [17]. Furthermore, the current study found significant reductions in the VAS scores from the day of surgery to postoperative 
days 3 and 7 in both groups $(\mathrm{P}<0.05)$. Al-Shamiri et al. found a significant reduction in the VAS pain score on postoperative day 3 from the day of surgery only in the preoperative group (dexamethasone) [18].

The maximum number of rescue analgesics administered was recorded on the day of surgery in both dexamethasone groups, with a mean of $1.30 \pm 0.95$ and $1.48 \pm 1.09$ tablets, respectively; it decreased postoperatively. No statistical difference was found between the groups during the follow-up. This result was similar to that of Mojsa et al. [17].

In conclusion, the effects of preoperative and postoperative injections of $4 \mathrm{mg}$ dexamethasone into the pterygomandibular space after LITM surgical removal were not significantly different. From this study, an injection of $4 \mathrm{mg}$ of dexamethasone into the pterygomandibular space is safe, and it provides a similar control of postoperative pain, facial swelling, and the restriction of mouth opening following LITM surgical removal if administered preoperatively or postoperatively.

\section{AUTHOR ORCDIS}

Kalaya Sitthisongkhram: https://orcid.org/0000-0002-1983-1918

Nattisa Niyomtham: https://orcid.org/0000-0003-2233-918X

Teeranut Chaiyasamut: https://orcid.org/0000-0003-0487-5333

Verasak Pairuchvej: https://orcid.org/0000-0002-9566-2407

Kumar KC: https://orcid.org/0000-0001-9620-7388

Natthamet Wongsirichat: https://orcid.org/0000-0003-3005-2680

\section{AUHOR GONHRBIIONS}

Kalaya Sitthisongkhram: Conceptualization, Data curation, Formal analysis, Investigation, Methodology

Nattisa Niyomtham: Visualization

Teeranut Chaiyasamut: Resources, Supervision, Visualization

Verasak Pairuchvej: Supervision, Visualization

Kumar KC: Visualization, Writing - original draft

Natthamet Wongsirichat: Project administration, Writing - review \& editing

ACKNOWLEDGEMENTS: The authors would like to thank their colleagues and the staff and dental assistants of the Department of Oral and Maxillofacial Surgery of the
Faculty of Dentistry of Mahidol University and the staff of the International College of Walailak University for the correction of the photographs in the manuscript. DECLARATION OF PATIENT CONSENT: The authors certify that they have obtained all appropriate patient consent forms. In the forms, the patient have given their consent for their images and other clinical information to be reported in the journal. The patients understand that their names and initials will not be published and due efforts will be made to conceal their identity, but anonymity cannot be guaranteed.

FUNDING AND SPONSORSHIP: This research did not have any funding.

CONFLICTS OF INTEREST: The authors declare no conflicts of interest.

ETHICS APPROVAL FOR CLINICAL STUDY: This study was approved by the Institutional Review Board (MU-DT/PY-IRB) of the Faculty of dentistry/Faculty of Pharmacy of Mahidol University with the approval number "COA. No. MU-DT/PY-IRB 2018/029.1505." CLINICAL TRIAL REGISTRATION: There is no requirement for this in our faculty because clinical research is controlled by the Ethical Committee of Research on Human Beings of the Dentistry and Pharmacy Department of Mahidol University.

\section{REFERENCES}

1. Dan AEB, Thygesen TH, Pinholt EM. Corticosteroid administration in oral and orthognathic surgery: a systematic review of the literature and meta-analysis. J Oral Maxillofac Surg 2010; 68: 2207-20.

2. Ngeow WC, Lim D. Do corticosteroids still have a role in the management of third molar surgery? Adv Ther 2016; 33: $1105-39$.

3. Chen Q, Chen J, Hu B, Feng G, Song J. Submucosal injection of dexamethasone reduces postoperative discomfort after third-molar extraction: a systematic review and meta-analysis. J Am Dent Assoc 2017; 148: 81-91.

4. Boonsiriseth K, Klongnoi B, Sirintawat N, Saengsirinavin 
C, Wongsirichat N. Comparative study of the effect of dexamethasone injection and consumption in lower third molar surgery. Int J Oral Maxillofac Surg 2012; 41: 244-7.

5. Graziani F, D'Aiuto F, Arduino PG, Tonelli M, Gabriele M. Perioperative dexamethasone reduces post-surgical sequelae of wisdom tooth removal. A split-mouth randomized double-masked clinical trial. Int J Oral Maxillofac Surg 2006; 35: 241-6.

6. Grossi GB, Maiorana C, Garramone RA, Borgonovo A, Beretta M, Farronato D, et al. Effect of submucosal injection of dexamethasone on postoperative discomfort after third molar surgery: a prospective study. J Oral Maxillofac Surg 2007; 65: 2218-26.

7. Klongnoi B, Kaewpradub P, Boonsiriseth K, Wongsirichat N. Effect of single dose preoperative intramuscular dexamethasone injection on lower impacted third molar surgery. Int J Oral Maxillofac Surg 2012; 41: 376-9.

8. Gozali P, Boonsiriseth K, Kiattavornchareon S, Khanijou M, Wongsirichat N. Decreased post-operative pain using a sublingual injection of dexamethasone $(8 \mathrm{mg})$ in lower third molar surgery. J Dent Anesth Pain Med 2017; 17: 47-53.

9. Antunes AA, Avelar RL, Martins Neto EC, Frota R, Dias E. Effect of two routes of administration of dexamethasone on pain, edema, and trismus in impacted lower third molar surgery. Oral Maxillofac Surg 2011; 15: 217-23.

10. Latt MM, Kiattavorncharoen S, Boonsiriseth K, Pairuchvej $\mathrm{V}$, Wongsirichat $\mathrm{N}$. The efficacy of dexamethasone injection on postoperative pain in lower third molar surgery. J Dent Anesth Pain Med 2016; 16: 95-102.

11. Bhargava D, Deshpande A, Khare P, Pandey SP, Thakur $\mathrm{N}$. Validation of data on the use of twin mix in minor oral surgery: comparative evaluation of efficacy of twin mix versus $2 \%$ lignocaine with 1:200000 epinephrine based on power analysis and an UV spectrometry study for chemical stability of the mixture. Oral Maxillofac Surg 2015; 19: $37-41$.

12. Bhargava D, Deshpande A, Thomas S, Sharma Y, Khare $\mathrm{P}$, Sahu SK, et al. High performance liquid chromatography determination of dexamethasone in plasma to evaluate its systemic absorption following intra-space pterygomandi- bular injection of twin-mix (mixture of $2 \%$ lignocaine with 1:200,000 epinephrine and $4 \mathrm{mg}$ dexamethasone): randomized control trial. Oral Maxillofac Surg 2016; 20: 259-64.

13. Bhargava D, Sreekumar K, Deshpande A. Effects of intra-space injection of twin mix versus intraoralsubmucosal, intramuscular, intravenous and per-oral administration of dexamethasone on post-operative sequelae after mandibular impacted third molar surgery: a preliminary clinical comparative study. Oral Maxillofac Surg 2014; 18: 293-6.

14. Singh K, Kumar S, Rathi VC, Rathi A, Bhati B. Comparison of post-operative sequelae of intra-space injection of twin mix versus intraoral-submucosal, intramuscular, intravenous and per-oral administration of dexamethasone after removal of impacted mandibular third molar. Int $\mathrm{J} \mathrm{Adv}$ Res 2016; 4: 552-7.

15. Moranon P, Chaiyasamut T, Sakdajeyont W, Vorakulpipat C, Klongnoi B, Kiattavornchareon S, et al. Dexamethasone injection into pterygomandibular space versus sublingual space on post-operative sequalae of lower third molar intervention. J Clin Med Res 2019; 11: 501-8.

16. Rocha-Neto AM, Nogueira EF, Borba PM, Laureano-Filho JR, Vasconcelos BC. Application of dexamethasone in the masseter muscle during the surgical removal of lower third molars. J Craniofac Surg 2017; 28: e43-e47.

17. Mojsa IM, Pokrowiecki R, Lipczynski K, Czerwonka D, Szczeklik K, Zaleska M. Effect of submucosal dexamethasone injection on postoperative pain, oedema, and trismus following mandibular third molar surgery: a prospective, randomized, double-blind clinical trial. Int J Oral Maxillofac Surg 2017; 46: 524-30.

18. Al-Shamiri HM, Shawky M, Hassanein N. Comparative Assessment of Preoperative versus Postoperative Dexamethasone on Postoperative Complications following Lower Third Molar Surgical Extraction. Int J Dent 2017; 2017: 1350375.

19. De Oliveira GS Jr, Almeida MD, Benzon HT, McCarthy RJ. Perioperative single dose systemic dexamethasone for postoperative pain: a meta-analysis of randomized controlled trials. Anesthesiology. 2011; 115: 575-88. 
20. Winter GB. Impacted third molars. St Louis. American Medical Book Co. 1926, pp 241-79.

21. Pell GJ, Gregory GT. Impacted mandibular third molars: Classification and Impacted mandibular third molars: Classification and modified technique for removal. Dent Dig 1933; 39: 330-8.

22. Schultze-Mosgau S, Schmelzeisen R, Frölich JC, Schmele H. Use of ibuprofen and methylprednisolone for the prevention of pain and swelling after removal of impacted third molars. J Oral Maxillofac Surg 1995; 53: 2-7.

23. Katz J, Melzack R. Measurement of pain. Surg Clin North Am 1999; 79: 231-52.

24. Sirintawat N, Sawang K, Chaiyasamut T, Wongsirichat N. Pain measurement in oral and maxillofacial surgery. J Dent Anesth Pain Med 2017; 17: 253-63.

25. Jensen MP, Chen C, Brugger AM. Interpretation of visual analog scale ratings and change scores: a reanalysis of two clinical trials of postoperative pain. J Pain 2003; 4: 407-14.

26. Daly B, Sharif MO, Newton T, Jones K, Worthington HV. Local interventions for the management of alveolar osteitis (dry socket). Cochrane Database Syst Rev 2012; 12: CD006968.

27. Bowe DC, Rogers S, Stassen LF. The management of dry socket/alveolar osteitis. J Ir Dent Assoc 2011-2012; 57: 305-10.
28. Xu JL, Sun L, Liu C, Sun ZH, Min X, Xia R. Effect of oral contraceptive use on the incidence of dry socket in females following impacted mandibular third molar extraction: a meta-analysis. Int J Oral Maxillofac Surg 2015; 44: 1160-5.

29. Bienek DR, Filliben JJ. Risk assessment and sensitivity meta-analysis of alveolar osteitis occurrence in oral contraceptive users. J Am Dent Assoc 2016; 147: 394-404.

30. Ata-Ali J, Ata-Ali F, Peñarrocha-Oltra D, Peñarrocha M. Corticosteroids use in controlling pain, swelling and trismus after lower third molar surgery. J Clin Exp Dent 2011; 3: 469-75.

31. Arora SS, Phull T, Kumar I, Kumar A, Kumar N, Singh H. A comparative study of the effect of two dosages of submucosal injection of dexamethasone on postoperative discomfort after third molar surgery: a prospective randomized study. Oral Maxillofac Surg 2018; 22: 225-30.

32. Waldron NH, Jones CA, Gan TJ, Allen TK, Habib AS. Impact of perioperative dexamethasone on postoperative analgesia and side-effects: systematic review and meta-analysis. Br J Anaesth 2013; 110: 191-200.

33. Majid OW. Submucosal dexamethasone injection improves quality of life measures after third molar surgery: a comparative study. J Oral Maxillofac Surg 2011; 69: 2289-97. 